\title{
Klein, J.-L. et Shearmur, R. (2017). Montréal : la cité des cités. Québec : Presses de l'Université du Québec, 300 p.
}

\author{
Leila Ghaffari ${ }^{\mathrm{a}}$
}

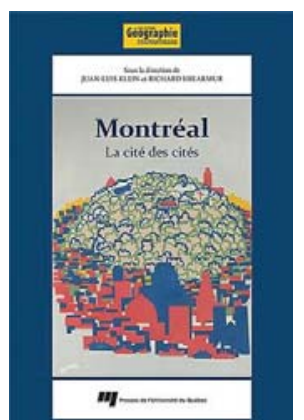

La ville de Montréal est le théâtre de trajectoires territoriales dans lequel, d'un côté, les quartiers représentent des identités distinctes et, de l'autre, des acteurs politiques essaient de présenter l'image d'un territoire unifié. Dans l'ouvrage Montréal: la cité des cités, les auteurs font un effort pour mettre en lumière cette diversité qui façonne la ville de Montréal et qui donne lieu à « une mosaïque de territoires » (p. 2). Des quartiers avec une identité distinctive claire ont été sélectionnés par les directeurs de cet ouvrage. Ces quartiers ont été regroupés en trois sections : des quartiers dans lesquels la culture joue un rôle important dans leur définition, des quartiers ouvriers qui ont subi une crise socioéconomique mais qui se revitalisent et des quartiers qui sont le lieu de projets structurants.

Dans la première partie du livre, les auteurs présentent une analyse de l'évolution des quartiers montréalais dans lesquels l'empreinte culturelle est visible, à savoir le Plateau-Mont-Royal (Kenza Benali), le Village gai (Colin Giraud) et le Quartier chinois (Jonathan Cha). Les auteurs démontrent comment la culture peut devenir le moteur d'une transformation urbaine inclusive, mais peut également générer l'exclusion. Cette partie se termine avec un chapitre sur le quartier Parc-Extension (Caroline Patsias), qui n'a pas une identité culturelle ancienne, mais dont les habitants s'en construisent une en réaction à l'exclusion sociale à laquelle fait face leur territoire. Ce quartier a pour défi de trouver sa place dans la structure politique de la ville.

Dans la deuxième partie du livre, les auteurs mettent en lumière les défis auxquels font face les anciens quartiers ouvriers de Montréal, lesquels vivent une reconstruction sociale, économique et identitaire. Quatre cas sont analysés dans ce contexte, à savoir le Sud-Ouest (Claire Poitras), le Mile End (Norma M. Rantisi et Deborah Leslie), le Technopôle Angus (Juan-Luis Klein, Jean-Marc Fontan et Benoît Lévesque) et La Petite-Patrie (Nik Luka). Les auteurs identifient les acteurs publics, privés et communautaires qui ont influencé la transformation de ces territoires pour mieux comprendre la scène sur laquelle ont lieu les changements. À travers cette analyse, le rôle des corporations de développement économique communautaire (CDEC) est mis de l'avant comme des instances qui ont réussi à fédérer les acteurs socioéconomiques, favorisant ainsi la coconstruction de la conversion des territoires. Cette section du livre met en évidence tout le potentiel que les quartiers ouvriers de Montréal représentent pour le développement local et, en même temps, les défis auxquels ils font face en raison de l'attrait suscité par leur transformation et la conséquente gentrification.

Dans la dernière partie du livre, les auteurs parlent des projets structurants qui essaient de modifier l'identité de certains territoires, à savoir le Quartier des Spectacles (Sylvain Lefebvre), le Quartier de l'innovation (Richard Shearmur), la Cité du multimédia (Diane-Gabrielle Tremblay) et la Cité des arts du cirque (Catherine Trudelle et Juan-Luis Klein). Le branding est le concept central de cette section de l'ouvrage.

a Doctorat en études urbaines, Université du Québec à Montréal et en aménagement, Université de Tours et assistante de recherche au CRISES 
Les auteurs montrent comment certains projets ont ciblé l'attraction de la classe créative, dans la perspective bien connue de Richard Florida, ce qui pose des enjeux identitaires forts. Dans le dernier chapitre, les auteurs présentent le cas de la TOHU à Saint-Michel qui, tout en s'inscrivant dans une dynamique de reconnaissance de Montréal comme une ville créative, parvient à enrichir le capital social de ce territoire défavorisé.

Dans cet ouvrage, les auteurs analysent le rôle joué par les acteurs qui interviennent dans la transformation des quartiers étudiés, tout en mettant de l'avant les enjeux que pose cette transformation, autant pour les acteurs socioéconomiques que pour la population locale. Le livre s'inscrit dans une logique systémique qui se base sur l'interdépendance des composantes de la ville, dont les quartiers, lesquels sont considérés comme « des systèmes dans un système » (p. 268), d'où la pertinence du titre de l'ouvrage. Dans ce contexte, Montréal : la cité des cités va à l'encontre de la vision centralisatrice de la ville et propose que le développement de la ville « devrait se faire selon une logique qui reconnaisse l'interdépendance fondamentale entre les participants à la ville, aussi bien les individus que les quartiers, et donc leur équité » (p. 268). 